\title{
Research on the Practice of Implicit Ideological and Political Education in Tertiary Institutions
}

\section{Yue Li}

\author{
Marxism College of Liaoning University, Shenyang, Liaoning, China
}

\begin{abstract}
Traditional explicit education on ideologies and politics in tertiary institutions is currently not operating at the desired level. On the contrary, implicit education on ideologies and politics is rising in response to the proper time and conditions due to its characteristics, advantages and the necessity. And the effectiveness of it in tertiary institutions can be enhanced by exerting its function of social practice, enhancing its function of campus environment, and constructing new media paths of it in tertiary institutions.
\end{abstract}

Key words: tertiary institutions; implicit ideological and political education; practice

\section{Introduction}

Ideological and political education is one of the most important links of tertiary institutions. The methods of it in tertiary institutions can be divided into two kinds: explicit ideological and political education and implicit ideological and political education, but the latter has not been recognized enough for a long time. "We should adhere to the unity of explicit education and implicit education, explore the ideological and political education resources contained in other courses and teaching methods, and achieve all-round education by all staff", said President Xi Jinping. This makes tertiary institutions pay more and more attention to the implicit ideological and political education, and has made a series of efforts to this.

\section{An Overview of Implicit Ideological and Political Education}

2.1 The basic meaning of implicit ideological and political education

"Implicit ideological and political education refers to the use of resources that are relatively implicit, hidden forms, culture, system, management, hidden curriculum and other ways to carry out education imperceptibly, so that those being educated can be inadvertently touched, shocked and moved, thus improving the quality of their morals and ideologies." Implicit ideological and political education means that educators are enjoined to employ the use of educational resources, exploit the potential available carriers, and hide the educational purpose in all kinds of teaching resources and carriers in a planned and purposeful way, thus imperceptibly affecting the ideological quality and spiritual realm of those being educated.

\subsection{The features of implicit ideological and political education}

First, the concealment and penetration of the educational purpose. Soviet educationist Sukhomlinsky believed that "the more concealed the educator's educational purpose is, the more likely it can be accepted by those educated, and the more it can be transformed into the inner needs of the students themselves." While implementing implicit education on 
ideologies and politics, traces of education should be diluted and the educated should be highly involved in the process of tutoring, in order to accept edification, influence and education imperceptibly.

Second, the feature and quality of transcending spatial and temporal limitations and being all-round. Implicit ideological and political education breaks through the conventional closed class teaching and indoctrination model of "ideological and political theory course", and transcends the limitation of time and space. It uses various resources and carriers of potential education on ideologies and politics around the educated, and arranges the teaching content flexibly, thus achieving all-round, multi-layer and three-dimensional education and the goal of education.

Third, flexibility and variability of the educational means. Implicit ideological and political education is not limited to theoretical indoctrination in the classroom, it can rather make use of a wider range of educational carriers, which cover such aspects as material, system, culture and spirit. In this way, the educators can adopt flexible and diversified educational means to carry out tutelage on ideologies and politics to the educated.

Fourth, lasting and deep-reaching educational effect. Implicit education on ideologies and politics requires learners to actively learn and integrate into the whole process of education, which can greatly deepen the feeling of participation, gaining, and also enhance the learner's sense of mission and responsibility. Therefore, implicit tutelage on ideologies and politics can gain more lasting and far-reaching educational effect.

\section{The Necessity for Tertiary Institutions to Undertake Implicit Ideological and Political Education}

Tertiary institutions are important places for tutee to live and study. Therefore, while paying attention to teaching scientific and cultural knowledge, tertiary institutions should also affix relevance to the study of the quality of morals and ideologies. In order to cultivate students into new socialist people with ideals and morals, tertiary institutions need to influence students through the appeal of implicit education on ideologies and politics.

3.1 Realize the need of unifying college education and self-education

Explicit ideological and political education is likely to be resisted by the educated, while the role and impact of implicit ideological and political education are obviously greater than that of explicit education. The process of implicit education on ideologies and politics is done unconsciously by the educated, and is the way of achieving educational purposes through imperceptible forms. At the same time, the process of being educated is also the process of value choice, which is a process for undergraduates to construct good moral and ideological quality and a process to realize the unification of college education and self-education.

3.2 Making up for the shortcomings of explicit ideological and political education in tertiary institutions

Traditional explicit ideological and political education has always been the mainstream way of ideological and political education in tertiary institutions. Its educational principle is indoctrination, which lacks communication and interaction between educated people, making it difficult to achieve lasting and far-reaching educational effect. While the implicit ideological and political education emphasizes the principle of subject selection. The educator and the educated are equal and interactive, so students can receive education unconsciously through internalization, making it an education method that influences students in an indirect and imperceptible way, and enabling it to have far-reaching and lasting influence.

3.3 Improving the actual effectiveness of ideological and political education in tertiary institutions

Nowadays, college students have distinctive personalities and characters, and are not interested in the theoretical knowledge of empty lectures. They hope to give play to their initiative and creativity in the learning process, and form their own values through their own analysis and judgment. But the content and methods of traditional education cannot be well 
accepted by students, let alone internalizing the content of traditional ideological and political education into their own moral qualities and behaviors. Therefore, tertiary institutions must adhere to the principle of the organic combination of explicit ideological and political education and implicit ideological and political education, so as to exert the maximum effect of both, thus doing well in the ideological and political education in tertiary institutions.

\section{Effective Measures that can Enhance Implicit Ideological and Political Education in Tertiary} Institutions

4.1 Giving play to the implicit ideological and political education function of social practice

As a crucial method of educating students on ideologies and politics in tertiary institutions, social practice takes up an integral place in improving the development of undergraduates and their comprehensive quality. "Social life is in its essence practical." People can transform their subjective world as well as the objective world in practical activities. And social practice is the premise for people to hold the right world view, outlook on life and values, the major factor driving the improvement of human thought, the purpose of human thought and understanding, and the only standard to test whether truth is true. In a word, only through their own practical activities, human beings can form a science oriented view of the world, life and values, so social practice undertakes an extremely crucial task in cultivating the ideological and political quality of the educated. Social practice can influence the students imperceptibly. This influence will not make the students rebellious, but will make college students have a deep impression of the content on education based on ideologies and politics in the process of social practice. Social investigation, visits, public welfare activities, volunteer services, workstudy and other practical activities can help undergraduates feel and experience "truth", "goodness" and "beauty", gain the sense of fulfillment, happiness and responsibility, enhance the spirit of autonomy, self-confidence and self-discipline, so that the students can enhance their own ideological and political accomplishment and level in practice.

4.2 Enhancing the implicit ideological and political education function of the campus environment

Implicit ideological and political education emphasizes the nature of concealing, penetration and life, and attaches importance to the students' status as the subject, fully considers the students' subject feelings, and takes the students' needs as the beginning to make learners receive education consciously in an imperceptible way. Therefore, in the process of ideological and political education, it is necessary to create a beautiful, healthy, optimistic, progressive campus material and cultural environment, so that the students can receive tutelage on ideologies and politics unknowingly. To enhance the function of implicit tutelage on ideologies and politics of campus environment, the first step is to totally exploit the ideologies and politics guiding ideology exists in the material and culture environment of the campus, including teaching buildings, student activity places, teaching facilities and so on, which contain rich ideological and political education "symbols". Fully exploiting the resources for tutelage on ideologies and politics contained in campus materials and endowing them with educational functions, which can affect the formation and development of the ideological and moral qualities of the student. Secondly, the resources for teaching politics and ideologies in the spirit and culture of the campus should be fully explored. Campus spirit and culture include school spirit, school motto, school emblem and other forms, which contains the spirit and school philosophy of the university. Fully exploiting the resources for teaching ideologies and politics in the spirit and culture of the campus can help create a unique spiritual environment atmosphere and strengthen the infiltration of spiritual culture, make the tutelage on ideologies and politics blend into the spirit and the educational philosophy of the university, thus subtly influencing college students' values and ideology and moral character, and shaping the character and soul of the college students. Finally, we should fully explore the resources on teaching ideologies and politics in the internal rules and regulations of the campus. The spiritual and cultural atmosphere created by university system culture is homely to the development of implicit tutelage on ideologies and politics in tertiary institutions. By 
constructing a scientific and reasonable university system with school-running characteristics, we can adapt to the conditions of the times, realize the guidance of educational values, clarify the direction, promote the ideological and political education in tertiary institutions in an implicit way, and improve the educational effect.

4.3 Constructing network and new media paths for implicit ideological and political education in tertiary institutions

First, tertiary institutions have to rely on the network to build a different platform for ideological and political education. New media such as Weibo, WeChat, QQ, etc., have a strong integration capacity and efficient communication power, and a profound effect on people's understanding and thinking habits. By building a new platform for teaching ideologies and politics and a bridge of network communication, colleges and universities can imperceptibly influence the cognition and value perception of college students with powerful network and real-time information, and carry out ideological and political education in an imperceptibly manner. Secondly, tertiary institutions should guide learners to make reasonable behavioral choices. In the micro era, the quick growth of mobile internet has had an integral effect on the change of undergraduates' discourse thinking and behaviors. College students prefer concise, vivid, humorous and closeto-life "micro" language in interpersonal communication and daily life. Tertiary institutions should employ the use of network language to find the convergence point between ideological and political education and the psychological characteristics of students, and use discourse processing art to spread core socialist values, so as to make students willing to listen to and practice what's taught.

In short, the development of implicit ideological and political education in tertiary institutions is to follow the rules of education and the rules of college students' ideological development. We should take students as the subject, give full play to the role of the implicit ideological and political education under the guidance of certain educational objectives, exploit implicit education resources, subtly change the students' thoughts, feelings and ideas, thus educating them in a relaxing atmosphere and helping them to internalize the education inside and externalizing it in their behaviors.

\section{Conflicts of Interest}

The author declares no conflicts of interest regarding the publication of this paper.

\section{About the author}

Yue Li, born in 1996 in Nanchong, Sichuan Province, postgraduate student, mainly research direction is basic problems of modern Chinese history.

\section{References}

[1] Xinhua News Agency. (2019). Xi Jinping Presided over the Convening of a Symposium on Teachers of Ideological and Political Theory Courses in Schools, Emphasizing the Use of Socialist Ideology with Chinese Characteristics in the New Era to Carry out the Party's Educational Policy and the Fundamental Task of Building Morality and Cultivating People. Wang Huning Attended the Symposium. Party Building, (04): 4-5.

[2] Zheng Y.T. (2010). Methodology of Ideological and Political Education. Higher Education Press, Beijing.

[3] Sukhomlynsky (1981). 100 Recommendations for Teachers. Tianjin People's Publishing House, Tianjin.

[4] Marx, Engels and Compilation of the Central Committee of the Communist Party of China Marx Engels Lenin Stalin Works Compilation Bureau. (1995). Selected Works of Marx and Engels (Volume I). People's Publishing Housing, Beijing. 